\title{
The Response Regulator ExpM Is Essential for the Virulence of Erwinia carotovora subsp. carotovora and Acts Negatively on the Sigma Factor RpoS $\left(\sigma^{\mathrm{S}}\right)$
}

\author{
Robert A. Andersson, ${ }^{1}$ E. Tapio Palva, ${ }^{2}$ and Minna Pirhonen ${ }^{1}$ \\ ${ }^{1}$ Department of Plant Biology, Uppsala Genetic Center, Swedish University of Agricultural Sciences, \\ Box 7080, SE-750 07 Uppsala, Sweden; '2Department of Biosciences, Division of Genetics, Box 56, \\ FIN-00014 University of Helsinki, Finland \\ Accepted 6 April 1999.
}

\begin{abstract}
The main virulence factors of Erwinia carotovora subsp. carotovora, the secreted, extracellular cell-wall-degrading enzymes, are controlled by several regulatory mechanisms. We have isolated transposon mutants with reduced virulence on tobacco. One of these mutants, with a mutation in a gene designated $\exp M$, was characterized in this study. This mutant produces slightly reduced amounts of extracellular enzymes in vitro and the secretion of the enzymes is also affected. The expM wild-type allele was cloned together with an upstream gene, designated $\exp L$, that has an unknown function. The expM gene was sequenced and found to encode a protein with similarity to the RssB/SprE protein of Escherichia coli and the MviA protein of Salmonella typhimurium. These proteins belong to a new type of two-component response regulators that negatively regulate the stability of the Sigma factor RpoS $\left(\sigma^{\mathbf{S}}\right)$ at the protein level. The results of this study suggest that ExpM has a similar function in $E$. carotovora subsp. carotovora. We also provide evidence that the overproduction of RpoS in the expM mutant is an important factor for the reduced virulence phenotype and that it partly causes the observed phenotype seen in vitro. However, an expM/rpoS double mutant is still affected in secretion of extracellular enzymes, suggesting that ExpM in addition to RpoS also acts on other targets.
\end{abstract}

Additional keywords: sensory kinase.

Erwinia carotovora subsp. carotovora causes diseases on many economically important plants. The main virulence factors of this pathogen are plant cell-wall-degrading enzymes including cellulases $(\mathrm{Cel})$, pectate lyases $(\mathrm{Pel})$, pectin lyase $(\mathrm{Pnl})$, protease (Prt), and polygalacturonase (Peh) (Collmer and Keen 1986; Pérombelon and Kelman 1980). The production of these enzymes, and hence virulence, in E. carotovora subsp. carotovora is tightly regulated by both positive and negative global regulators as shown by various mutants affected in enzyme production and virulence (Chatterjee et al.

Corresponding author: Minna Pirhonen; Telephone: +46 186733 16; Fax: +46 186732 79; E-mail: Minna.Pirhonen@ vbiol.slu.se

Nucleotide and/or amino acid sequence data have been submitted to the EMBL data base as accession number AJ224437.
1995; Cui et al. 1995, 1996; Eriksson et al. 1998; Frederick et al. 1997; Harris et al. 1998; Jones et al. 1993; Liu et al. 1993; Mukherjee et al. 1996; Murata et al. 1991, 1994; Pirhonen et al. 1991, 1993; Thomson et al. 1997). These regulators include genes such as the aepA gene, which encodes a putative membrane protein that is supposed to transfer a plant signal (Liu et al. 1993; Murata et al. 1991) and the $r \mathrm{smB}$ gene (formerly aepH), which encodes a novel regulatory RNA that is also involved in the regulation of enzyme production (Liu et al. 1998; Murata et al. 1994). Others encode products, ExpI/RexI, that direct the synthesis of a diffusible signal molecule, the Erwinia autoinducer (EAI; Jones et al. 1993; Pirhonen et al. 1993). Other characterized regulators are members of two-component systems (ExpA, ExpS, and RpfA; Eriksson et al. 1998; Frederick et al. 1997). Negative regulators have also been found: the hexA gene, which encodes a member of the LysR family of transcriptional regulators (Harris et al. 1998); and the rsmA gene, which directs the synthesis of an RNA-binding protein (Cui et al. 1995; Liu et al. 1998; Mukherjee et al. 1996).

A new type of response regulator protein has recently been found in Escherichia coli and Salmonella typhimurium, RssB (also called SprE) and MviA, respectively. These proteins seem not to be DNA binding; instead, they negatively regulate the stability of the $\sigma^{S}$ protein, a subunit of the RNA polymerase encoded by the rpoS gene (Bearson et al. 1996; Benjamin et al. 1996; Bösl 1993; Muffler et al. 1996a; Pratt and Silhavy 1996). In E. coli, RpoS is a regulator of stationary phase-induced genes and also of a number of genes needed during stress conditions (for review see Hengge-Aronis 1996; Ishihama 1997; Loewen and Hengge-Aronis 1994; Loewen et al. 1998). RpoS is a very unstable protein in growing cells but is stabilized during entry into stationary phase or during osmotic stress (Lange and Hengge-Aronis 1994; Muffler et al. 1996b). RssB has been shown to be a key regulator of the stability of the RpoS protein (Muffler et al. 1996a; Pratt and Silhavy 1996). The turnover of RpoS in E. coli is dependent on the ClpXP protease (Pratt and Silhavy 1996; Schweder et al. 1996), but RssB has been proposed to interact directly with RpoS and not with the protease itself (Zhou and Gottesman 1998). In S. typhimurium, RpoS has been shown to be important for virulence to mice (Fang et al. 1992). The mviA gene has also been shown to influence the virulence of this patho- 
gen to mice (Benjamin et al. 1986, 1991; Swords et al. 1997b). Recently, the rpoS gene from E. carotovora subsp. carotovora was cloned and characterized (Calcutt et al. 1998; Mukherjee et al. 1998). Interestingly, RpoS is not needed for virulence in the E. carotovora subsp. carotovora strain 71 . Instead, an rpoS mutant was found to be slightly more virulent than the parental strain, probably because RpoS acts as a positive regulator of $r s m A$ that in turn acts negatively on the production of virulence factors (Mukherjee et al. 1998).

In this work we describe the characterization of an $E$. carotovora subsp. carotovora transposon mutant with reduced virulence on tobacco and potato. We have also characterized the corresponding gene, $\exp M$, and we show that it encodes a protein with similarity to a new group of response regulators represented by the RssB protein from E. coli (Bösl 1993; Muffler et al. 1996a; Pratt and Silhavy 1996) and the MviA protein from S. typhimurium (Benjamin et al. 1996). In this study, we show for the first time that this type of response regulator is involved in the production and secretion of virulence factors in a plant-pathogenic bacterium and that it, similarly to RssB and MviA, acts negatively on RpoS. We also show that the overproduction of RpoS partly causes the phenotype of the expM mutant.

\section{RESULTS}

\section{Isolation of a transposon mutant with reduced virulence on tobacco and potato.}

We have used transposon mutagenesis to isolate E. carotovora subsp. carotovora mutants affected in virulence (Pirhonen et al. 1991). The mutants showing reduced virulence could be classified into several classes based on virulence, motility, and enzyme production. One of the classes comprised three strains unable to produce Pnl after induction with mitomycin $\mathrm{C}$ (class $\mathrm{Pnl}^{-}$). In this study, we have characterized the virulence and extracellular enzyme production of one of the mutants in this class, strain SCC 3032. The mutant showed reduced virulence on tobacco (see below), the plant that was used to screen the virulence of the transposon mutants (Pirhonen et al. 1991). To study the virulence of this mutant on a natural host of the pathogen, we assayed the virulence of the mutant on greenhouse-grown potato as described earlier (McMillan et al. 1993). The result of this experiment shows that SCC3032 has reduced virulence in the potato stem assay (data not shown).

\section{The mutant SCC3032 is affected in the production and secretion of several extracellular enzymes.}

The mutant SCC3032 was originally characterized as producing only $20 \%$ of the wild-type level of Pnl after induction with mitomycin $\mathrm{C}$, while it resembled the wild- type strain on indicator plates (Pirhonen et al. 1991). To verify that the transposon insert giving kanamycin resistance was the reason for the observed mutant phenotype the mutation was transduced to clean background (SCC3193) by T4GT transduction. One of the transductants was characterized further in this work. To characterize the extracellular enzyme production of the mutant in more detail we performed enzyme assays and Northern (RNA) blot analysis on cells grown in L medium supplemented with $0.4 \%$ polygalacturonic acid (PGA) to induce the extracellular enzyme production. We characterized the amounts of Pel, Peh, Prt, and Cel both in the supernatant and in the cell fraction. The results show that the total amount of Peh was reduced in the mutant while the total Pel activity was similar to that in the wild-type strain SCC3193. The mutant strain was also affected in the secretion of the enzymes as higher levels of enzyme activities were measured from the cell fraction (Fig. 1A). Furthermore, we found that the activity of Prt in the supernatant from the mutant was much lower (Fig. 1A). Since Prt is not active inside the cells (Kyösti et al. 1991; Wandersman 1989; Wandersman et al. 1990) we were not able to measure the total Prt activity. SCC3032 also had lower Cel activity in the supernatant, compared with SCC3193 (data not shown). The accumulation of pehA and pelC transcripts was slightly reduced in the mutant, compared with the wild type level (Fig. 1B). To localize the cell bound enzyme activities in the mutant strain SCC3032, periplasmic proteins were isolated
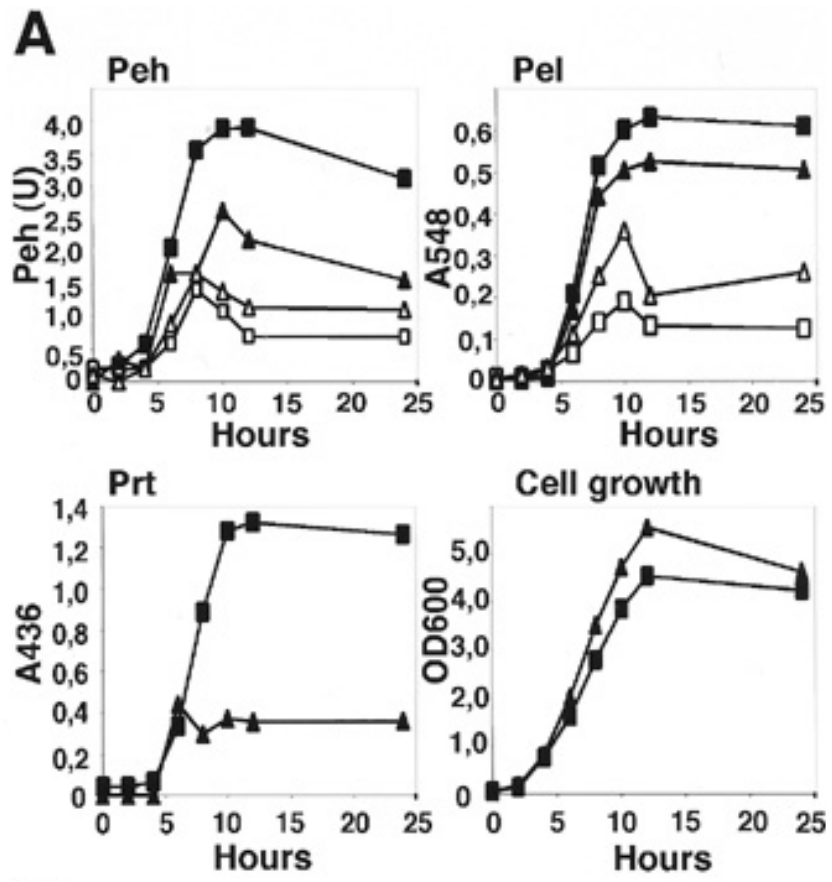

B
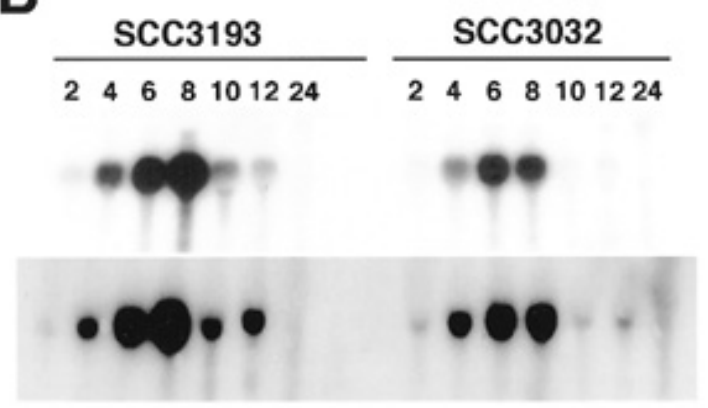

Fig. 1. A, Graphs showing the enzyme activities of polygalacturonase (Peh), pectate lyase (Pel), and protease (Prt), and the growth of the cells from which the samples were collected. Squares represent the wild-type SCC3193; triangles represent the SCC3032 mutant. For the Peh and Pel graphs, closed symbols indicate enzyme activity in the supernatants and open symbols indicate enzyme activity in the cell fractions. B, Northern (RNA) blots showing the mRNA accumulation of pehA (upper panel) and pelC (lower panel) transcripts. Five micrograms of RNA was loaded in each lane. Samples were taken at different timepoints as indicated. 
and Pel and Peh activities were assayed from culture supernatant, periplasmic fraction, and sonicated cells (Table 1). In the mutant, higher levels of enzymes accumulated in the periplasmic fraction.

We also analyzed the amount of the diffusible signal molecule (EAI) since it is known that the level of EAI influences both production and secretion of the extracellular enzymes in SCC3193 (Pirhonen et al. 1991, 1993). We were unable to detect any difference in EAI production between SCC3032 and SCC3193 (data not shown). Taken together, our results show that the SCC3032 mutant is affected in the production and secretion of the extracellular enzymes.

\section{Cloning of the mutated allele.}

In order to identify the mutated allele in SCC3032, the kanamycin resistance gene and the flanking chromosomal DNA were cloned into a pBluescript II plasmid (see Materials and Methods). We sequenced the DNA flanking the transposon and found three open reading frames (ORFs), two complete and one partial (Fig. 2A). The second ORF, expM (extracellular enzyme production), interrupted by the transposon, encodes a response regulator protein similar to the RssB protein of E. coli (Bösl 1993; Muffler et al. 1996a; Pratt and Silhavy 1996) and the MviA protein of S. typhimurium (Benjamin et al. 1996) (Fig. 2B). The overall amino acid identity between ExpM and the other two proteins is $64 \%$ for RssB and $62 \%$ for MviA. A search in the sequence data bases revealed that the first ORF, dedicated $\operatorname{expL}$, has high homology (66\% identity at the DNA level) to the $r s s A$ gene of $E$. coli (Bösl 1993; Muffler et al. 1996a), a gene found upstream of $r s s B$. The sequence data suggest that the $\exp L$ and $\exp M$ genes may be organized in an operon similarly to the $\operatorname{rss} A B$ genes of $E$. coli. The third partial ORF downstream of expM has homology $(75 \%$ identity at the DNA level over the first $190 \mathrm{bp}$ ) to the $5^{\prime}$ end of the galU gene of E. coli (Weissborn et al. 1994). The GalU protein is an enzyme that catalyzes the formation of UDP-glucose and mutations in this gene give sensitivity to galactose (Fukasawa et al. 1963). Jayaswal et al. (1985) reported that an E. carotovora subsp. carotovora mutant defective in the production of GalU is sensitive to galactose and has reduced virulence. They concluded that the galactose-sensitive phenotype of this mutant is the reason for its reduced virulence. Therefore, we tested whether SCC3032 is

Table 1. Cellular localization of pectate lyase (Pel) and polygalacturonase (Peh)

\begin{tabular}{|c|c|c|c|c|c|c|}
\hline \multirow[b]{2}{*}{ Enzyme } & \multirow[b]{2}{*}{ Strain } & \multirow[b]{2}{*}{$\mathrm{OD}_{600}$} & \multicolumn{4}{|c|}{ Distribution $^{\mathbf{b}}$} \\
\hline & & & $\begin{array}{c}\text { Total } \\
\text { activity }\end{array}$ & $\begin{array}{l}\text { Super- } \\
\text { natant }\end{array}$ & $\begin{array}{l}\text { Peri- } \\
\text { plasm }\end{array}$ & Cells \\
\hline Pel & SCC3193 & 2.74 & 0.72 & 79 & 13 & 8 \\
\hline Pel & SCC 3032 & 4.07 & 0.67 & 62 & 24 & 14 \\
\hline Peh & SCC 3193 & 2.74 & 3.55 & 70 & 21 & 9 \\
\hline Peh & SCC 3032 & 4.07 & 2.46 & 44 & 50 & 6 \\
\hline
\end{tabular}

${ }^{a}$ Cells were grown in $\mathrm{L}$ medium supplemented with $0.4 \%$ polygalacturonic acid for $10 \mathrm{~h}$ to the $\mathrm{OD}_{600}$ indicated. Fractionation of the cells and enzyme assays were performed as described earlier (Pirhonen et al. 1991). Pel activity is given as absorbance $\left(A_{548}\right)$ and the Peh activity in units $(0.1 \mu \mathrm{mol}$ of glucose equivalent per min).

${ }^{b}$ Distribution of the enzymes is shown as a percentage of the total activities. SCC3193 is the wild-type strain and SCC3032 the expM mutant strain. Results shown are means of two samples. sensitive to galactose. We found that this is not the case (data not shown), which shows that the mutant phenotype of SCC3032 is not caused by a polar effect on the galU gene.

\section{The $\exp M$ mutant has elevated levels of the sigma factor RpoS.}

The ExpM homologs in E. coli and S. typhimurium have been found to negatively regulate the stability of the RpoS protein (Bearson et al. 1996; Muffler et al. 1996a; Pratt and Silhavy 1996). To gain more information about the function of ExpM we performed a Western blot (immunoblot) analysis with an E. coli RpoS antisera (Jishage and Ishihama 1995) in order to examine whether ExpM affected RpoS also in $E$. carotovora subsp. carotovora. Samples were collected from the same cultures used for enzyme assays and Northern blots (Fig. 1). The results of this experiment show that the expM mutant contains elevated levels of RpoS (Fig. 3A). We also performed a Northern blot with an $r p o S$ probe and found that there is no significant difference in the accumulation of rpoS transcript between SCC3193 and SCC3032 (Fig. 3B). This suggests that ExpM is a negative regulator of RpoS and that it most likely acts on the stability of the RpoS protein, similarly to RssB and MviA. Mukherjee et al. (1998) recently showed that RpoS positively regulates the $r s m A$ gene that encodes a negative regulator of virulence and extracellular enzyme production in the E. carotovora subsp. carotovora strain 71 . They also provided evidence that the phenotype of the rpoS mutant is caused by the reduced expression of $r s m A$ in the $r p o S$ mutant. Therefore, we performed a Northern blot analysis to check whether the increased amounts of RpoS in SCC3032 caused higher accumulation of $r s m A$ transcript. The result shows that the $\operatorname{rsmA}$ transcript accumulates to a higher level in SCC3032, compared with the wild-type strain (Fig. 3C).

\section{The reduced virulence of the SCC3032 mutant on tobacco can be complemented by the expLM clone.}

To characterize expM further we cloned the expLM genes under the control of the promoter upstream of $\operatorname{expL}$. We amplified these genes and about $350 \mathrm{bp}$ of the DNA upstream of $\operatorname{expL}$ by PCR (polymerase chain reaction) with the proofreading polymerase $P f u$. The resulting fragment (Fig. 2A) was cloned into the low-copy-number vector pACYC177 to obtain pRA911 (for details, see Materials and Methods). To check whether pRA911 was able to complement the reduced virulence of SCC 3032 we performed a virulence test on tobacco seedlings (Fig. 4A). This experiment shows that pRA911 complements the reduced virulence phenotype of the mutant. We have also tested the ability of pRA911 to restore the production and secretion of extracellular enzymes in SCC3032 when the cells are grown in vitro. We could detect only a very slight increase in the amount of the enzymes produced and secreted by SCC 3032 carrying pRA911, compared with SCC3032 carrying pACYC177 (data not shown). We have also tested complementation with a plasmid carrying the expM gene under control of the lac promoter in pBluescript (pRA909). This construct was able to complement the virulence of SCC3032 on tobacco although the level of complementation was not as high as with pRA911. However, no complementation of the enzyme production in vitro could be detected (data not shown). We have 
also tested whether pRA911 affected the overproduction of RpoS when introduced into SCC3032 (Fig. 4B). We performed a Western blot with RpoS antibodies and the result shows that the amount of RpoS is significantly reduced in SCC3032 harboring pRA911, compared with SCC3032 harboring the empty vector pACYC177.
The phenotype of the $\exp M$ mutant strain can partly be explained by the overproduction of RpoS.

It has recently been shown that an E. carotovora subsp. carotovora rpoS mutant of the strain 71 has higher levels of extracellular enzymes in the supernatant and increased virulence (Mukherjee et al. 1998). Similarly, the strain SCC8003,

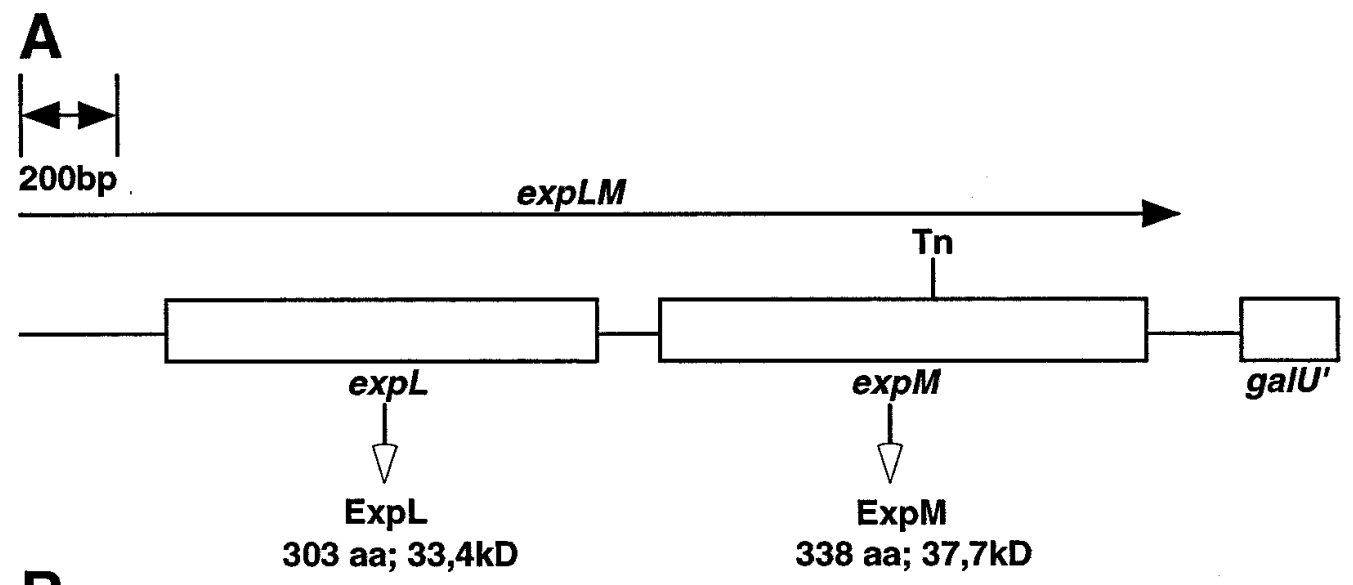

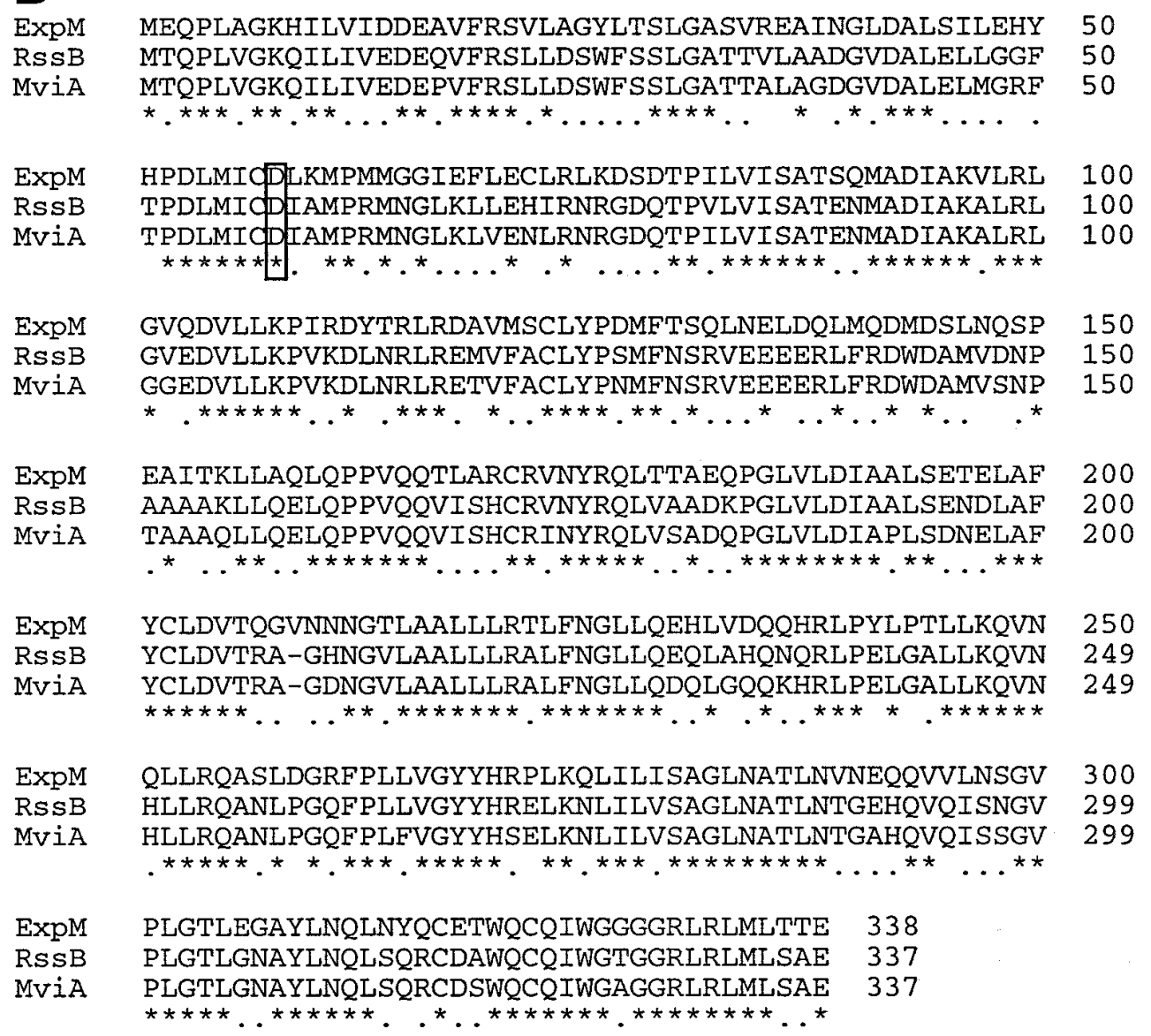

Fig. 2. A, Schematic drawing in scale over the expLM locus. Calculated sizes of the ExpL and ExpM polypeptides are shown. The expLM PCR (polymerase chain reaction) fragment cloned into pACYC177 to obtain pRA911 and a galU-like gene downstream of expLM are indicated. Position of the transposon in SCC3032 is indicated. B, Alignment of the ExpM polypeptide of Erwinia carotovora subsp. carotovora, RssB from Escherichia coli (Bösl 1993; Muffler et al. 1996a) and MviA from Salmonella typhimurium (Benjamin et al. 1996). Identical amino acids are indicated with asterisks and similar amino acids with dots. Amino acid identity between ExpM and RssB is 64\%; identity between ExpM and MviA is 62\%. Conserved aspartate residue that has been shown to be phosphorylated in RssB (Bouché et al. 1998) is boxed. 
an $r p o S$ mutant of SCC3193, also has increased virulence on tobacco although the extracellular enzyme activities in vitro are similar to those of SCC3193 (data not shown). In order to find out whether the overproduction of RpoS was the reason for the observed phenotype of the expM mutant we constructed an expM/rpoS double mutant strain, SCC8004, by transducing the mutated expM allele from SCC3032 to the rpoS mutant strain SCC8003. The double mutant was tested for extracellular enzyme production in vitro and for virulence on tobacco. The results from the enzyme assays (Table 2) show that the double mutant produces slightly more Peh, when compared with SCC3032, but is still impaired in the secretion of Peh and Pel. The amounts of Prt and Cel in the supernatants from SCC8004 and SCC3032 were found to be similar (data not shown). If the overproduction of RpoS caused by the mutation in $\exp M$ were the only reason for the reduced virulence of SCC3032, we would expect the double mutant to have a virulence similar to that of the $\operatorname{rpoS}$ mutant strain SCC8003. We performed a virulence test on tobacco
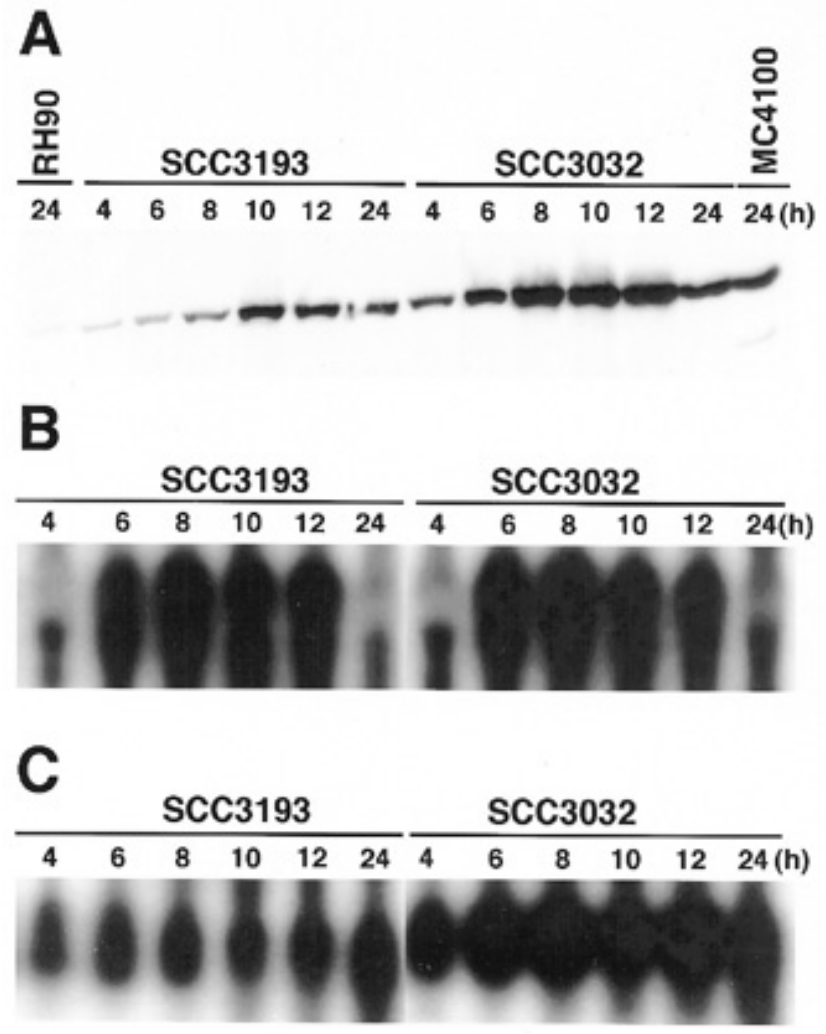

Fig. 3. A, Western blot (immunoblot) with Escherichia coli RpoS antisera (Jishage and Ishihama 1995) showing overproduction of RpoS in the $\exp M$ mutant strain (SCC3032), compared with the wild-type strain (SCC3193). The E. coli strains MC4100 and RH90 (MC4100 rpoS359::Tn10) serve as positive and negative controls, respectively, in order to identify the RpoS band. Samples were collected at time points indicated from the same cultures as in Figure 1. Ten micrograms of protein was loaded in each lane. B, Northern (RNA) blot showing accumulation of rpoS transcripts in the wild-type strain SCC3193, compared with the expM mutant strain SCC3032. Ten micrograms of RNA was loaded in each lane. Samples were taken from the same cells as in A. C, Northern blot showing accumulation of $\operatorname{rsmA}$ transcripts in the wild-type strain SCC3193, compared with the expM mutant strain SCC3032. Ten micrograms of RNA was loaded in each lane. Samples were taken from the same cells as in $\mathbf{A}$ and $\mathbf{B}$. seedlings and found that SCC8004 has slightly lower virulence than SCC8003 (Fig. 5), which indicates that the overproduction of RpoS is important but is not the only reason for the reduced virulence of the $\exp M$ mutant.

\section{DISCUSSION}

We have used transposon mutagenesis to identify genes that are needed for the virulence of E. carotovora subsp. carotovora (Pirhonen et al. 1991). In this study, we report the characterization of one of the mutant strains, SCC3032, showing reduced virulence on tobacco and potato. This strain has a mutation in a gene that seems to be important for the full production and secretion of several extracellular enzymes. Total enzyme activities are lower in the mutant than in the parental strain, and a large part of the residual activities are found inside the cells.

We cloned the kanamycin resistance gene and the flanking chromosomal DNA from the strain SCC3032 and sequenced the flanking DNA. The transposon was found to be inserted in an ORF that was designated expM (extracellular enzyme production). When we used the $\exp M$ sequence to search the data bases we found that homologs of expM have been characterized in E. coli, rssB (Bösl 1993; Muffler et al. 1996a; Pratt

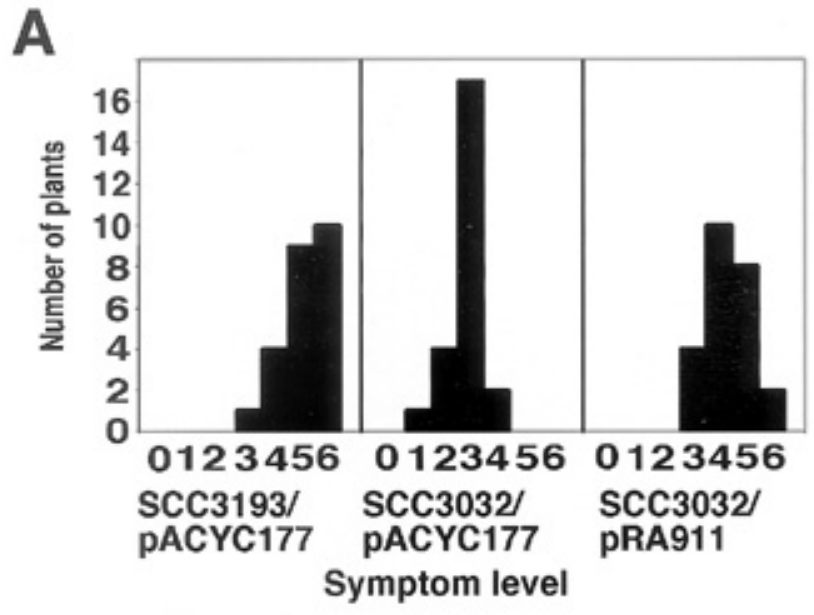

B.
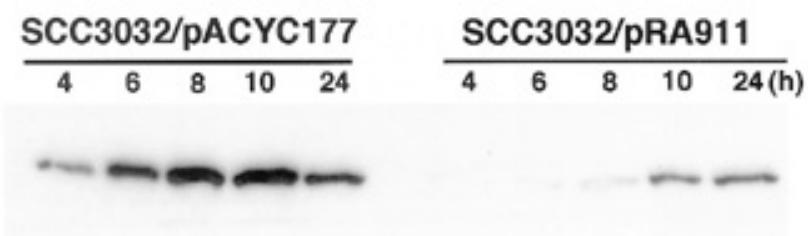

Fig. 4. Complementation of the expM mutant by the pRA911 plasmid. A, Complementation of the reduced virulence. Assay was performed on tobacco seedlings as described by Pirhonen et al. (1993). Symptoms were scored $72 \mathrm{~h}$ after infection. Symptom levels (0-6): $0=$ no symptom; 1 = clear infection of 1 leaf; $2=1$ or 2 leaves totally macerated; $3=$ several leaves macerated; $4=$ half plant infected; $5=$ only a few leaves uninfected; $6=$ whole plant totally macerated. SCC3193 represents the wild-type strain and the plasmid pACYC177 is an empty vector control. B, Western blot (immunoblot) with Escherichia coli RpoS antisera (Jishage and Ishihama 1995). Cells were grown in L medium containing $0.4 \%$ PGA to the various time points as shown. Ten micrograms of protein was loaded in each lane. 
and Silhavy 1996), and S. typhimurium, mviA (Bearson et al. 1996; Benjamin et al. 1996). In both E. coli and $S$. typhimurium, the product of the rss B/mviA genes encodes a response regulator protein that negatively regulates the stability of the stationary phase Sigma factor $\sigma^{\mathrm{S}}$, encoded by the rpoS gene. RssB and MviA have been classified as response regulators since their $\mathrm{N}$ termini have high homology to traditional response regulators while their $\mathrm{C}$ termini do not share homology to other proteins in the data base. Furthermore, RssB was recently shown to be phosphorylated at the predicted position (Asp-58) by acetyl phosphate in vitro (Bouché et al. 1998). Mutants affected in RssB/MviA show elevated production of RpoS, especially during exponential growth phase when this protein is known to be unstable (for a recent review of the RpoS regulation see Loewen et al. 1998, and references therein). In E. coli, RssB has been suggested to interact directly with RpoS although the degradation of RpoS is depend-

Table 2. Enzyme activities in the expM/rpoS double mutant strain SCC8004

\begin{tabular}{lccccc}
\hline & & & \multicolumn{3}{c}{ Distribution $^{\mathbf{b}}$} \\
\cline { 5 - 6 } Enzyme $^{\mathbf{a}}$ & Strain & OD $_{\mathbf{6 0 0}}$ & Total & Supernatant & Cell fraction $^{\mathbf{c}}$ \\
\hline Pel & SCC3193 & 3.42 & 0.85 & 64 & 36 \\
Pel & SCC3032 & 4.79 & 0.83 & 49 & 51 \\
Pel & SCC8004 & 3.41 & 0.75 & 49 & 51 \\
Peh & SCC3193 & 3.42 & 4.8 & 67 & 33 \\
Peh & SCC3032 & 4.79 & 3.3 & 52 & 48 \\
Peh & SCC8004 & 3.41 & 4.1 & 39 & 61 \\
\hline
\end{tabular}

${ }^{a}$ Pel refers to pectate lyase and Peh to polygalacturonase. Cells were grown for $10 \mathrm{~h}$ in $\mathrm{L}$ medium containing $0.4 \%$ polygalacturonic acid to the $\mathrm{OD}_{600}$ indicated. Enzyme assays were performed as described earlier (Pirhonen et al. 1991). Pel activity is given as absorbance $\left(A_{548}\right)$ and Peh activity in units $(0.1 \mu \mathrm{mol}$ of glucose equivalent per min). SCC3193 is the wild-type strain, SCC3032 the expM mutant strain, and SCC8004 the expM/rpoS double mutant.

${ }^{b}$ Distribution of the enzymes is shown as a percentage of the total activities.

${ }^{c}$ Cell fraction includes enzymes from both periplasmic and cell fractions.

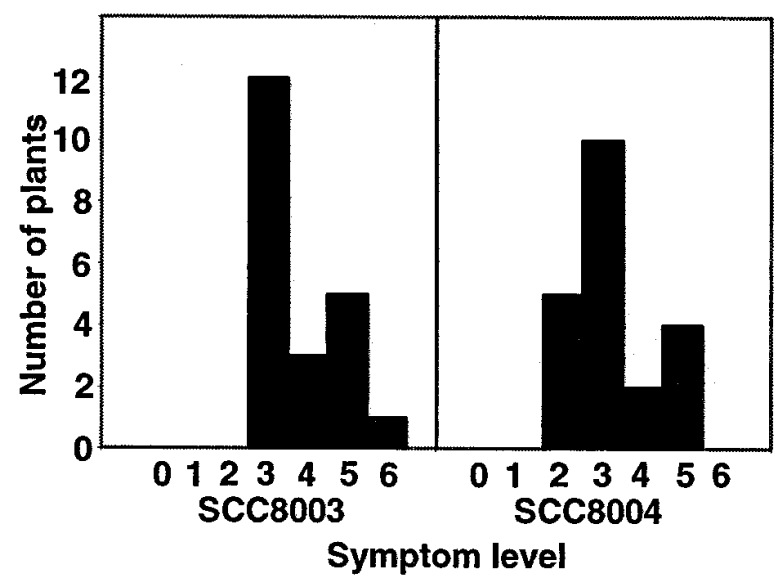

Fig. 5. Virulence of the expM/rpoS double mutant SCC 8004 compared with the rpoS mutant strain SCC8003 on tobacco seedlings. Symptoms were scored $48 \mathrm{~h}$ after infection. Symptom levels (0-6): $0=$ no symptom; $1=$ clear infection of 1 leaf; $2=1$ or 2 leaves totally macerated; $3=$ several leaves macerated; $4=$ half plant infected; $5=$ only a few leaves uninfected; $6=$ whole plant totally macerated. ent on the ClpXP protease (Pratt and Silhavy 1996; Schweder et al. 1996). When degradation is blocked by a $c l p P$ mutation, RssB still downregulates RpoS activity, indicating that RssB also modulates the activity of RpoS (Zhou and Gottesman 1998). The high amino acid identity between ExpM and RssB/MviA prompted us to investigate whether ExpM had a similar function in the regulation of RpoS. Our Western blot with E. coli RpoS antisera shows that a similar mechanism exists in E. carotovora subsp. carotovora, as the expM mutant produces elevated levels of RpoS. We also found that there is no significant difference in the accumulation of rpoS transcript in the $\exp M$ mutant strain. This together with the high similarity between ExpM and RssB/MviA and the fact that all three proteins seem to lack a DNA-binding domain suggest that ExpM regulates the stability of the RpoS protein and possibly also affects its activity.

Recently, it was found that the LysR homolog LrhA modulates the activity of RssB in E. coli (Gibson and Silhavy 1999). Interestingly, LrhA is a homolog of PecT in Erwinia chrysanthemi (Surgey et al. 1996) and HexA in E. carotovora subsp. carotovora (Harris et al. 1998). These two genes have been shown to act as negative regulators of extracellular enzyme production. Although it has been shown that PecT directly interacts with the regulatory regions of Pel genes (Castillo et al. 1998), it is possible that PecT/HexA in addition acts on ExpM.

When the mutated allele in SCC3032 was isolated and sequenced we discovered that the expM gene may be organized in an operon together with an upstream gene designated $\exp L$. The expL gene was found to be homologous to the $r s s A$ gene in E. coli. The possible function of $\exp L$ is still unclear but the fact that this gene seems to be organized in an operon together with the $\exp M$ gene suggests that they are involved in similar processes. In support of that, Muffler et al. (1996a) reported that RssA seems to act in the same pathway as RssB although its exact function is unclear. ExpL, especially the $\mathrm{N}$ terminus, shares some homology to proteins from various organisms in the data bases although their functions are mostly unknown. However, ExpL is clearly not a classical two-component sensory kinase.

To further study the role of $\exp M$, we cloned the wild-type $\exp L M$ alleles into a low-copy-number plasmid and found that the resulting plasmid, pRA911, was able to complement the reduced virulence of the expM mutant on tobacco. However, we could not observe any complementation of the reduced extracellular enzyme production in vitro when pRA911 was introduced into SCC 3032. The reason for these contradictory findings regarding the complementation of the mutant phenotype is not known. A similar problem was reported by Yildez and Schoolnik (1998). They isolated an rpoS mutant of Vibrio cholerae and found that this mutant was affected in the production and/or secretion of hemagglutinin/protease and that it was impaired in the ability to survive certain environmental stresses in vitro. The latter phenotype could be complemented by a plasmid carrying rpoS from $V$. cholerae but the same plasmid could not complement the production and/or secretion of hemagglutinin/protease. These results, together with ours, indicate that the optimal level of RpoS might vary for different target genes or depending on environmental factors.

In $S$. typhimurium, rpoS mutants show reduced virulence to mice (Fang et al. 1992) and mviA has also been shown to be 
involved in the regulation of virulence to mice. Most lineages become avirulent when mviA is inactivated while others become virulent upon inactivation of $m v i A$ due to a mutation in rpoS (Benjamin et al. 1986, 1991; Swords et al. 1997a, 1997b; Wilmes-Riesenberg et al. 1997). mviA null mutations give rise to a change in colony morphology called the small colony morphology phenotype (in lineages without the $\operatorname{rpoS}$ mutation mentioned above), probably due to inappropriate expression of RpoS-regulated genes (Bearson et al. 1996; Swords et al. 1997b). We could not detect any such change in colony morphology in the isolated expM mutant or after transduction of the mutated allele to the wild-type strain SCC3193 (data not shown).

The rpoS gene from E. carotovora subsp. carotovora 71 was recently cloned and functionally expressed in $E$. coli (Calcutt et al. 1998). Later, (Mukherjee et al. 1998) constructed and characterized an E. carotovora subsp. carotovora rpoS mutant. Their results show that this mutant had enhanced production of virulence factors and elevated virulence. They also discovered that RpoS positively regulates the negative regulator $r s m A$ that encodes an RNA-binding protein that acts by destabilizing various transcripts (Liu et al. 1998). They also provided evidence that the reduced expression of $r s m A$ is the reason for the phenotype of the rpoS mutant. We have obtained similar results in virulence tests with SCC8003, an rpoS mutant of strain SCC3193. In order to find out whether the overproduction of RpoS was the reason for the observed phenotype in the expM mutant, we constructed an expM/rpoS double mutant by transducing the mutated expM allele into SCC8003. We expected that the double mutant, SCC8004, would have a phenotype similar to that of SCC 8003 if the expM mutation would manifest itself only through the overproduction of RpoS. When we examined the extracellular enzymes from SCC8004 grown in vitro we found that it was still affected in the secretion similarly to the $\exp M$ mutant strain. However, it had slightly increased total production of Peh. We found that the Prt and Cel activities in the supernatant were similar in SCC3032 and SCC8004. We conclude that in vitro the expM mutation mainly affects the production/secretion of Prt and the secretion of Peh and Pel and that this phenotype is not mediated by the overexpression of RpoS. We found that the amounts of pehA transcripts were higher in SCC8004 than in SCC3032, while both mutants had similar levels of pelC transcripts. However, the amounts of these transcripts in SCC8004 were still lower than in the wild type (data not shown). Our results also show that the overproduction of RpoS partly causes the reduced virulence on tobacco since the double mutant has elevated virulence, compared with SCC3032, but still retains lower virulence than SCC8003. We have also tested the virulence of SCC8004 carrying pRA911 and found that the virulence on tobacco seedlings increased slightly, compared with SCC8004 carrying the empty vector pACYC177. However, the introduction of pRA911 into SCC8004 did not alter the in vitro phenotype. We were able to detect elevated levels of $r s m A$ transcript in the expM mutant while the double mutant strain as expected accumulated lower levels of $r s m A$ transcripts, especially when the cultures reached higher cell densities (data not shown).

Taken together, our results suggest that a lack of virulence factors other than the extracellular enzymes may also contribute to the reduced virulence of the expM mutant in our system and that the production of these factors is complemented by pRA911 and restored by the inactivation of $r p o S$ in the expM mutant background.

\section{MATERIALS AND METHODS}

\section{Bacterial strains, plasmids, culture conditions, and chemicals.}

The E. carotovora subsp. carotovora wild-type strain SCC3193 has been described (Pirhonen and Palva 1988). The expM mutant strain SCC3032 was isolated by Pirhonen et al. (1991) and characterized in this study. The $r p o S$ mutant SCC8003 and the expM/rpoS double mutant strain SCC8004 were constructed in this study (see below). The E. coli strain DH5 $\alpha$ (Hanahan 1983) was used for plasmid maintenance and preparations. Plasmid vectors used were pBluescript II (Stratagene, La Jolla, CA) and pACYC177 that we obtained from New England Biolabs (Beverly, MA). The E. coli strains MC4100 (CGSC\#6152) and RH90 (MC4100 rpoS359::Tn10) (Lange and Hengge-Aronis 1991) have been described. The pHV200I ${ }^{-}$plasmid carrying the lux genes from Vibrio fischeri with a frame-shift mutation in luxI has been described (Pearson et al. 1994). E. carotovora subsp. carotovora was grown at $28^{\circ} \mathrm{C}$ in L medium (Miller 1972). For enzyme assays and Northern/Western analysis the L medium was supplemented with $0.4 \%$ PGA (P-1879; Sigma, St. Louis, MO) in order to enhance the enzyme production. The E. coli cells were grown in $\mathrm{L}$ medium at $37^{\circ} \mathrm{C}$. Ampicillin $(150 \mu \mathrm{g} / \mathrm{ml})$, kanamycin $(25 \mu \mathrm{g} / \mathrm{ml})$, and chloramphenicol $(25 \mu \mathrm{g} / \mathrm{ml})$ were added when appropriate. Kanamycin and chloramphenicol were not used during the collection of samples for Northern analysis, Western analysis, and enzyme assays to avoid possible negative antibiotic effects. Transfer of plasmids was done by electroporation (E. carotovora subsp. carotovora) with a BioRad gene pulser (Bio-Rad, Hercules, CA) or by a standard transformation technique (E. coli). Restriction enzymes, ligase, multiprime labeling kit, and radiolabeled $\left[{ }^{32} \mathrm{P}\right] \mathrm{dATP}$ for Northern analysis and $\left[{ }^{35} \mathrm{~S}\right] \mathrm{dATP}$ for DNA sequencing were from MBI Fermentas (Vilnius, Lithuania) or Amersham Pharmacia Biotech (Buckinghamshire, UK). All PCRs were carried out with the proof-reading polymerase Pfu (Stratagene, La Jolla, CA). Synthetic oligonucleotides were from Kebo Lab (Stockholm, Sweden). Plasmids were isolated by plasmid purification kits from Qiagen (Hilden, Germany) and the PCRs were cleaned with the QiaQuick PCR purification kit from Qiagen.

\section{Cloning techniques and DNA sequencing.}

The mutated expM allele was cloned by the following strategy: chromosomal DNA from SCC3032 was cut into completion with EcoRI. The resulting fragments were ligated to EcoRI-digested pBluescriptII and transformed to E. coli. The mutant allele with flanking chromosomal DNA was isolated by selecting for the kanamycin resistance of the transposon. The flanking DNA (2.8 kb) was then sequenced. The obtained sequence was used to generate oligonucleotides for PCR in order to clone the $\exp L M$ and $\exp M$ wild-type alleles. The expLM genes were cloned as follows: The $5^{\prime}$ primer contained a HindIII site. The resulting 2.4-kb PCR fragment was purified, cleaved with HindIII, and ligated to HindIII/SmaIdigested pACYC177 to obtain pRA911. The expM gene was cloned by a $5^{\prime}$ primer designed to amplify the coding region of 
expM plus the ribosome-binding site. This primer had a BamHI site and the resulting fragment was cloned into pBluescript II in order to get expression from the lac promoter of the vector. This construct was named pRA909. The 3' primer used was the same for both constructs. The restriction pattern of these clones was analyzed and relevant parts were sequenced. The expM/rpoS double mutant strain was constructed as follows: The rpoS gene from SCC3193 was cloned into pACYC177 by PCR with primers designed with the help of known rpoS sequences. This construct was named pRA910 and the rpoS gene was sequenced (R. A. Andersson, V. Kõiv, and M. Pirhonen, unpublished). In order to mutate the rpoS gene we inserted the $\Omega-\mathrm{Cm}$ resistance marker from $\mathrm{pHP} 45 \Omega$ $\mathrm{Cm}$ (Fellay et al. 1987) into the unique EcoRV site located $260 \mathrm{bp}$ downstream of the translational start codon. The rpoS gene with this insertion was amplified with PCR and the resulting fragment was cloned into the SmaI site of pBluescript II. We then digested this construction with EcoRI/XbaI and isolated the 5-kb fragment containing the mutated $r p o S$ allele. This fragment was ligated into EcoRI/XbaI-digested pUTKm1 (de Lorenzo and Timmis 1994). pUT-Km1 carries the $\lambda$ pir-dependent R6K origin of replication, which does not replicate in bacteria that lack $\lambda$ pir. The mobile unit of pUT-Km1 was cut out with EcoRI and XbaI and replaced with the fragment carrying the rpoS gene interrupted by $\Omega-\mathrm{Cm}$. The resulting plasmid was mobilized by conjugation from $E$. coli S17-1 $\lambda$ pir into the E. carotovora subsp. carotovora wild-type strain SCC3193 as described (de Lorenzo and Timmis 1994). Transconjugants were selected for the $\mathrm{Cm}$ resistance gene used for gene inactivation on minimal medium (M9) with glycerol $(0.4 \%)$ and then tested for the loss of the vector marker (Amp). The Amp ${ }^{\mathrm{s}}$ transconjugants were first screened by Western blots with antisera to $E$. coli RpoS. One of the mutants that did not produce RpoS was chosen for further studies and named SCC8003. We then constructed the expM/rpoS double mutant strain SCC 8004 by transducing the mutated $\operatorname{expM}$ allele from SCC3032 into SCC8003. This mutant was also checked by Western blot and found not to produce any RpoS protein. We also performed a Southern blot that showed that the $\Omega-\mathrm{Cm}$ fragment and the $\mathrm{Km}$ resistance marker were inserted into $\operatorname{rpoS}$ and $\operatorname{expM}$, respectively. Finally, Northern analysis showed that no $\operatorname{rpoS}$ transcript could be detected. Transduction of the mutated $\exp M$ allele was done with the phage T4GT7 (Wilson et al. 1979) as described (Pirhonen et al. 1991).

DNA sequencing was performed by cycle sequencing with a Taq Dye Deoxy Terminator Cycle Sequencing Kit and a 373A DNA sequencer (Applied Biosystems, Foster City, CA) or by the dideoxy chain termination method (Sanger et al. 1977) with the DNA sequencing kit from United States Biochemicals (Cleveland, $\mathrm{OH}$ ). New primers for sequencing were designed based on the obtained sequences. The complete sequence of both strands was determined for the 2,797-bp flanking the transposon. The sequence data were analyzed with the PC Gene (Oxford Molecular, Oxford, UK) program. Southern blots were performed essentially according to Southern (1975).

\section{Cell fractionation and enzyme assays.}

Cell fractionation was done according to Pirhonen et al. (1991). Peh, Pel, Cel, and Prt activities were assayed and calculated as described (Pirhonen et al. 1991).

\section{Virulence tests.}

The tobacco plants (Nicotiana tabacum cv. Samsun) used for virulence tests were cultivated as described by Pirhonen et al. (1991). Virulence tests on tobacco were performed essentially as described in Pirhonen et al. (1993) and the symptoms were scored after 48 or $72 \mathrm{~h}$. Virulence tests on potato stems were performed on greenhouse-grown potato (Solanum tuberosum $\mathrm{cv}$. Bintje) with a toothpick to infect the plants directly in the stem as described by McMillan et al. (1993) and the symptoms were followed for $72 \mathrm{~h}$.

\section{RNA isolation and Northern analysis.}

RNA was isolated from E. carotovora subsp. carotovora cells with the Qiagen RNA isolation kit (Qiagen, Hilden, Germany). Samples were collected during $24 \mathrm{~h}$ of growth and frozen in liquid nitrogen before RNA isolation. The RNA ( $5 \mu \mathrm{g}$ per lane for the pehA and pelC blots or $10 \mu \mathrm{g}$ per lane for the $r p o S$ and $r s m A$ blots) was separated by formaldehyde gel electrophoresis and blotted onto nylon membranes (Amersham, Buckinghamshire, UK). The filters were hybridized overnight at $65^{\circ} \mathrm{C}$. As probes we used specific fragments from pelC (Heikinheimo et al. 1995), pehA (Saarilahti et al. 1990), rpoS (R. A. Andersson, V. Kõiv, and M. Pirhonen, unpublished), and $r s m A$ (R. A. Andersson, unpublished). The probes were labeled with $\left[{ }^{32} \mathrm{P}\right] \mathrm{dATP}$ by random priming. Filters were washed $15 \mathrm{~min}$ in $6 \times \mathrm{SSC}(1 \times$ $\mathrm{SSC}$ is $0.15 \mathrm{M} \mathrm{NaCl}$ plus $0.015 \mathrm{M}$ sodium citrate), $0.5 \%$ SDS (sodium dodecyl sulfate), and then twice for 15 min plus once for $30 \mathrm{~min}$ in $1 \times \mathrm{SSC}, 0.5 \%$ SDS. After being washed, the filters were analyzed with a PhosphorImager machine (Molecular Dynamics, Sunnyvale, CA) and on X-ray film.

\section{Protein extraction, protein concentration measurements, and Western blot analysis.}

The E. carotovora subsp. carotovora cells were grown overnight in $\mathrm{L}$ medium and subcultured 1:50 into a 50-ml culture (L medium containing $0.4 \%$ PGA). The cultures were then grown to various time points ( 4 to $24 \mathrm{~h}$ ). The $E$. coli strains MC4100 and RH90 were grown to stationary phase in $5 \mathrm{ml}$ of L medium. Samples were removed at each time point and the cells were pelleted and frozen before protein extraction, which was done as follows: The cells were washed in TE buffer (10 mM Tris, $1 \mathrm{mM}$ EDTA pH 8.0) and lysed by lysozyme $(4 \mu \mathrm{g} / \mathrm{ml})$ on ice. They were then briefly sonicated and the cell debris was removed by centrifugation. The protein concentration in the supernatant was determined by the Bradford method with reagents from Bio-Rad (Hercules, CA). Protein $(10 \mu \mathrm{g})$ of each sample was loaded on $12 \%$ Bio-Rad Tris- $\mathrm{HCl}$ ready gels. The gel was blotted onto a nitrocellulose filter (Amersham Hybond-C). The filter was blocked for $1 \mathrm{~h}$ in TBS (1× TBS is $20 \mathrm{mM}$ Tris plus $500 \mathrm{mM} \mathrm{NaCl}, \mathrm{pH} 7.5$ ) containing $5 \%$ milk powder and $0.05 \%$ Tween. A 1:4,000 dilution of E. coli RpoS antisera (Jishage and Ishihama 1995) was added in TBS containing $1 \%$ milk powder and $0.05 \%$ Tween. The filter was washed five times ( $5 \mathrm{~min}$ each) in TBS containing $0.05 \%$ Tween. A secondary antibody (peroxidase labeled goat anti-rabbit; Amersham Pharmacia Biotech) was added in the same buffer as the primary antibody, incubated for $1 \mathrm{~h}$, and washed as above except that the two last washes were done in TBS without Tween. The blots were then developed by the ECL system (Amersham Pharmacia Biotech) according to the instructions given by the manufacturer. 


\section{Galactose sensitivity test and autoinducer concentration measurement.}

Galactose sensitivity was assayed by growing the strains in $\mathrm{L}$ medium in the presence of $0.4 \%$ galactose. Galactosesensitive, T4-resistant mutants (Pirhonen et al. 1991) were used as negative control. The amount of EAI was determined by a bioassay. The E. coli strain DH5 $\alpha$ harboring the pHV200I ${ }^{-}$plasmid was mixed with supernatant from SCC3193 and SCC3032. The light production and hence the EAI concentration were then measured in a luminometer machine (Bio-Orbit, Turku, Finland).

\section{ACKNOWLEDGMENTS}

We thank Maj-Britt Karlsson, Mona Munther, and Gunvor Sandman for excellent technical assistance. We are grateful to Viia Kõiv for sharing unpublished data. Jan Svensson and Anders Eriksson are thanked for helpful advice during some of the experiments. We also thank Akira Ishihama for kindly providing the E. coli RpoS antisera. The E. coli strain RH90 was provided by Regine Hengge-Aronis. The plasmid pHV200I ${ }^{-}$was kindly provided by Kendall Gray and E. P. Greenberg. This work was supported by the Swedish Council for Forestry and Agricultural Research, the Nilsson-Ehle foundation, the Royal Swedish Academy of Sciences (von Beskows foundation), P. O. Lundells foundation (Uppsala University), Stina and Richard Högbergs foundation (SLU), and Oscar and Lili Lamms foundation.

\section{LITERATURE CITED}

Bearson, S. M., Benjamin, W. H., Jr., Swords, W. E., and Foster, J. W. 1996. Acid shock induction of RpoS is mediated by the mouse virulence gene mviA of Salmonella typhimurium. J. Bacteriol. 178:25722579.

Benjamin, W. H., Jr., Turnbough, C. L., Jr., Posey, B. S., and Briles, D. E. 1986. Salmonella typhimurium virulence genes necessary to exploit the $I t y^{s / s}$ genotype of the mouse. Infect. Immun. 51:872-878.

Benjamin, W. H., Jr., Wu, X., and Swords, W. E. 1996. The predicted amino acid sequence of the Salmonella typhimurium virulence gene $m v i A^{+}$strongly indicates that MviA is a regulator protein of a previously unknown $S$. typhimurium response regulator family. Infect. Immun. 64:2365-2367.

Benjamin, W. H., Jr., Yother, J., Hall, P., and Briles, D. E. 1991. The Salmonella typhimurium locus mviA regulates virulence in 1 ty ${ }^{\mathrm{s}}$ but not lty ${ }^{\mathrm{r}}$ mice: Functional mviA results in avirulence; mutant (nonfunctional) $m v i A$ results in virulence. J. Exp. Med. 174:1073-1083.

Bösl, M. R. 1993. Genetic map of the tyrT region of Escherichia coli from 27.1 to 27.7 minutes based exclusively on sequence data. J. Bacteriol. 175:7751-7753.

Bouché, S., Klauck, E., Fischer, D., Lucassen, M., Jung, K., and Hengge-Aronis, R. 1998. Regulation of RssB-dependent proteolysis in Escherichia coli: A role for acetyl phosphate in a response regulator-controlled process. Mol. Microbiol. 27:787-795.

Calcutt, M. J., Becker-Hapak, M., Gaut, M., Hoerter, J., and Eisenstark, A. 1998. The rpoS gene of Erwinia carotovora: Gene organization and functional expression in E. coli. FEMS Microbiol. Lett. 159:275281.

Castillo, A., Nasser, W., Condemine, G., and Reverchon, S. 1998. The PecT repressor interacts with regulatory regions of pectate lyase genes in Erwinia chrysanthemi. Biochim. Biophys. Acta 1442:148-160.

Chatterjee, A., Cui, Y., Liu, Y., Dumenyo, C. K., and Chatterjee, A. K. 1995. Inactivation of $r s m A$ leads to overproduction of extracellular pectinases, cellulases, and proteases in Erwinia carotovora subsp. carotovora in the absence of the starvation/cell density sensing signal, $N$-(3-oxohexanoyl)-L-homoserine lactone. Appl. Environ. Microbiol. 61:1959-1967.

Collmer, A., and Keen, N. T. 1986. The role of pectic enzymes in plant pathogenesis. Annu. Rev. Phytopathol. 24:383-409.

Cui, Y., Chatterjee, A., Liu, Y., Dumenyo, C. K., and Chatterjee, A. K. 1995. Identification of a global repressor gene, rsmA, of Erwinia carotovora subsp. carotovora that controls extracellular enzymes, $\mathrm{N}$ -
(3-oxohexanoyl)-L-homoserine lactone, and pathogenicity in softrotting Erwinia spp. J. Bacteriol. 177: 5108-5115.

Cui, Y., Madi, L., Mukherjee, A., Dumenyo, C. K., and Chatterjee, A. K. 1996. The RsmA- mutants of Erwinia carotovora subsp. carotovora strain Ecc71 overexpress $h r p N_{E c c}$ and elicit a hypersensitive reactionlike response in tobacco leaves. Mol. Plant-Microbe Interact. 9:565573.

de Lorenzo, V., and Timmis, K. N. 1994. Analysis and construction of stable phenotypes in gram-negative bacteria with $\mathrm{Tn} 5$ - and $\mathrm{Tn} 10$ derived minitransposons. Methods Enzymol. 235:386-405.

Eriksson, A. R. B., Andersson, R. A., Pirhonen, M., and Palva, E. T. 1998. Two-component regulators involved in the global control of virulence in Erwinia carotovora subsp. carotovora. Mol. PlantMicrobe Interact. 11:743-752.

Fang, F. C., Libby, S. J., Buchmeier, N. A., Loewen, P. C., Switala, J., Harwood, J., and Guiney, D. C. 1992. The alternative $\sigma$ factor KatF (RpoS) regulates Salmonella virulence. Proc. Natl. Acad. Sci. USA 89:11978-11982.

Fellay, R., Frey, J., and Krisch, H. 1987. Interposon mutagenesis of soil and water bacteria: A family of DNA fragments designed for in vitro insertional mutagenesis of gram-negative bacteria. Gene 52:147-154.

Frederick, R. D., Chiu, J., Bennetzen, J. L., and Handa, A. K. 1997. Identification of a pathogenicity locus, rpfA, in Erwinia carotovora subsp. carotovora that encodes a two-component sensor-regulator protein. Mol. Plant-Microbe Interact. 10:407-415.

Fukasawa, T., Jokura, K., and Kurahashi, K. 1963. Mutations in Escherichia coli that affect uridine diphosphate glucose pyrophosphorylase activity and galactose fermentation. Biochim. Biophys. Acta 74:608-620.

Gibson, K. E., and Silhavy, T. J. 1999. The LysR homolog LrhA promotes RpoS degradation by modulating activity of the response regulator SprE. J. Bacteriol. 181:563-571.

Hanahan, D. 1983. Studies on transformation of Escherichia coli with plasmids. J. Mol. Biol. 166:557-580.

Harris, S. J., Shih, Y.-L., Bentley, S. D., and Salmond, G. P. C. 1998. The hexA gene of Erwinia carotovora encodes a LysR homologue and regulates motility and the expression of multiple virulence determinants. Mol. Microbiol. 28:705-717.

Heikinheimo, R., Flego, D., Pirhonen, M., Karlsson, M.-B., Eriksson, A., Mäe, A., Kõiv, V., and Palva, E. T. 1995. Characterization of a novel pectate lyase from Erwinia carotovora subsp. carotovora. Mol. Plant-Microbe Interact. 8:207-217.

Hengge-Aronis, R. 1996. Back to log phase: $\sigma^{\mathrm{s}}$ as a global regulator in the osmotic control of gene expression in Escherichia coli. Mol. Microbiol. 21:887-893.

Ishihama, A. 1997. Adaptation of gene expression in stationary phase bacteria. Curr. Opin. Genet. Dev. 7:582-588.

Jayaswal, R. K., Bressan, R. A., and Handa, A. K. 1985. Effects of a mutation that eliminates UDP glucose-pyrophosphorylase on the pathogenicity of Erwinia carotovora subsp. carotovora. J. Bacteriol. 164: 473-476.

Jishage, M., and Ishihama, A. 1995. Regulation of RNA polymerase sigma subunit synthesis in Escherichia coli: Intracellular levels of sigma 70 and sigma 38. J. Bacteriol. 177:6832-6835.

Jones, S., Yu, B., Bainton, N. J., Birdsall, M., Bycroft, B. W., Chhabra, S. R., Cox, A. J. R., Golby, P., Reeves, P. J., Stephans, S., Winson, M. K., Salmond, G. P. C., Stewart, G. S. A. B., and Williams, P. 1993. The lux autoinducer regulates the production of exoenzyme virulence determinants in Erwinia carotovora and Pseudomonas aeruginosa. EMBO J. 12:2477-2482.

Kyösti, S. R. M., Cramer, C. L., and Lacy, G. H. 1991. Erwinia carotovora subsp. carotovora extracellular protease: Characterization and nucleotide sequence of the gene. J. Bacteriol. 173:6537-6546.

Lange, R., and Hengge-Aronis, R. 1991. Identification of a central regulator of stationary-phase gene expression in Escherichia coli. Mol. Microbiol. 5:49-59.

Lange, R., and Hengge-Aronis, R. 1994. The cellular concentration of the $\sigma^{\mathrm{s}}$ subunit of RNA polymerase in Escherichia coli is controlled at the levels of transcription, translation, and protein stability. Genes Dev. 8:1600-1612.

Liu, Y., Cui, Y., Mukherjee, A., and Chatterjee, A. K. 1998. Characterization of a novel RNA regulator of Erwinia carotovora ssp. carotovora that controls production of extracellular enzymes and secondary metabolites. Mol. Microbiol. 29:219-234. 
Liu, Y., Murata, H., Chatterjee, A., and Chatterjee, A. K. 1993. Characterization of a novel regulatory gene aepA that controls extracellular enzyme production in the phytopathogenic bacterium Erwinia carotovora subsp. carotovora. Mol. Plant-Microbe Interact. 6:299-308.

Loewen, P. C., and Hengge-Aronis, R. 1994. The role of the sigma factor $\sigma^{\mathrm{S}}(\mathrm{KatF})$ in bacterial global regulation. Annu. Rev. Microbiol. 48: 53-80.

Loewen, P. C., Hu, B., Strutinsky, J., and Sparling, R. 1998. Regulation in the rpoS regulon of Escherichia coli. Can. J. Microbiol. 44:707717.

McMillan, G. P., Hedley, D., Fyffe, L., and Pérombelon, M. C. M. 1993. Potato resistance to soft-rot erwinias is related to cell wall pectin esterification. Physiol. Mol. Plant Pathol. 42:279-289.

Miller, J. H. 1972. Experiments in Molecular Genetics. Cold Spring Harbor Laboratory, Cold Spring Harbor, NY. p. 466.

Muffler, A., Fischer, D., Altuvia, S., Storz, G., and Hengge-Aronis, R. 1996a. The response regulator RssB controls stability of the $\sigma^{\mathrm{s}}$ subunit of RNA polymerase in Escherichia coli. EMBO J. 15:13331339.

Muffler, A., Traulsen, D. D., Lange, R., and Hengge-Aronis, R. 1996b. Posttranscriptional osmotic regulation of the $\sigma^{\mathrm{s}}$ subunit of RNA polymerase in Escherichia coli. J. Bacteriol. 178:1607-1613.

Mukherjee, A., Cui, Y., Liu, Y., Dumenyo, C. K., and Chatterjee, A. K. 1996. Global regulation in Erwinia species by Erwinia carotovora rsmA, a homologue of Escherichia coli csrA: Repression of secondary metabolites, pathogenicity and hypersensitive reaction. Microbiology 142:427-434

Mukherjee, A., Cui, Y., Ma, W., Liu, Y., Ishihama, A., Eisenstark, A., and Chatterjee, A. K. 1998. RpoS (Sigma-S) controls expression of rsmA, a global regulator of secondary metabolites, harpin, and extracellular proteins in Erwinia carotovora. J. Bacteriol. 180:3629-3634.

Murata, H., Chatterjee, A., Liu, Y., and Chatterjee, A. K. 1994. Regulation of the production of extracellular pectinase, cellulase, and protease in the soft rot bacterium Erwinia carotovora subsp. carotovora: Evidence that aepH of E. carotovora subsp. carotovora 71 activates gene expression in E. carotovora subsp. carotovora, E. carotovora subsp. atroseptica, and Escherichia coli. Appl. Environ. Microbiol. 60:3150-3159.

Murata, H., McEvoy, J. L., Chatterjee, A., Collmer, A., and Chatterjee, A. K. 1991. Molecular cloning of an aepA gene that activates production of extracellular pectolytic, cellulolytic, and proteolytic enzymes in Erwinia carotovora subsp. carotovora. Mol. Plant-Microbe Interact. 4:239-246.

Pearson, J. P., Gray, K. M., Passador, L., Tucker, K. D., Eberhard, A., Iglewski, B. H., and Greenberg, E. P. 1994. Structure of the autoinducer required for expression of Pseudomonas aeruginosa virulence genes. Proc. Natl. Acad. Sci. USA 91:197-201.

Pérombelon, M. C. M., and Kelman, A. 1980. Ecology of the soft rot Erwinias. Annu. Rev. Phytopathol. 18:361-387.

Pirhonen, M., Flego, D., Heikinheimo, R., and Palva, E. T. 1993. A small diffusible signal molecule is responsible for the global control of virulence and exoenzyme production in the plant pathogen Erwinia carotovora. EMBO J. 12:2467-2476.
Pirhonen, M., and Palva, E. T. 1988. Occurrence of bacteriophage T4 receptor in Erwinia carotovora. Mol. Gen. Genet. 214:170-172.

Pirhonen, M., Saarilahti, H., Karlsson, M.-B., and Palva, E. T. 1991 Identification of pathogenicity determinants of Erwinia carotovora subsp. carotovora by transposon mutagenesis. Mol. Plant-Microbe Interact. 4:276-283.

Pratt, L. A., and Silhavy, T. J. 1996. The response regulator SprE controls the stability of RpoS. Proc. Natl. Acad. Sci. USA 93:2488-2492.

Saarilahti, H. T., Heino, P., Pakkanen, R., Kalkkinen, N., Palva, I., and Palva, E. T. 1990. Structural analysis of the pehA gene and characterization of its protein product, endopolygalacturonase, of Erwinia carotovora subspecies carotovora. Mol. Microbiol. 4:1037-1044.

Sanger, F., Nicklen, S., and Coulson, A. R. 1977. DNA-sequencing with chain-terminating inhibitors. Proc. Natl. Acad. Sci. USA 74:54635467.

Schweder, T., Lee, K.-H., Lomovskaya, O., and Matin, A. 1996. Regulation of Escherichia coli starvation sigma factor $\left(\sigma^{\mathrm{s}}\right)$ by ClpXP protease. J. Bacteriol. 178:470-476.

Southern, E. M. 1975. Detection of specific sequences among DNA fragments separated by gel electrophoresis. J. Mol. Biol. 98:503-517.

Surgey, N., Robert-Baudouy, J., and Condemine, G. 1996. The Erwinia chrysanthemi pecT gene regulates pectinase gene expression. J. Bacteriol. 178:1593-1599.

Swords, W. E., Cannon, B. M., and Benjamin, W. H., Jr. 1997a. Avirulence of LT2 strains of Salmonella typhimurium results from a defective rpoS gene. Infect. Immun. 65:2451-2453.

Swords, W. E., Giddings, A., and Benjamin, W. H., Jr. 1997b. Bacterial phenotypes mediated by mviA and their relationship to the mouse virulence of Salmonella typhimurium. Microb. Pathog. 22:353-362.

Thomson, N. R., Cox, A., Bycroft, B. W., Stewart, G. S. A. B., Williams, P., and Salmond, G. P. C. 1997. The Rap and Hor proteins of Erwinia, Serratia, and Yersinia: A novel subgroup in a growing superfamily of proteins regulating diverse physiological processes in bacterial pathogens. Mol. Microbiol. 26:531-544.

Wandersman, C. 1989. Secretion, processing and activation of bacterial extracellular proteases. Mol. Microbiol. 3:1825-1831.

Wandersman, C., Delepelaire, P., and Letoffe, S. 1990. Secretion processing and activation of Erwinia chrysanthemi proteases. Biochimie 72:143-146.

Weissborn, A. C., Liu, Q., Rumley, M. K., and Kennedy, E. P. 1994. UTP: Alpha-D-glucose-1-phosphate uridylyltransferase of Escherichia coli: Isolation and DNA sequence of the galU gene and purification of the enzyme. J. Bacteriol. 176:2611-2618.

Wilmes-Riesenberg, M. R., Foster, J. W., and Curtiss, R., III. 1997. An altered $\operatorname{rpoS}$ allele contributes to the avirulence of Salmonella typhimurium LT2. Infect. Immun. 65:203-210.

Wilson, G. G., Young, K. K. Y., Edlin, G. J., and Konigsberg, W. 1979. High-frequency generalised transduction by bacteriophage T4. Nature 280:80-82.

Yildez, F. H., and Schoolnik, G. K. 1998. Role of rpoS in stress survival and virulence of Vibrio cholerae. J. Bacteriol. 180:773-784.

Zhou, Y., and Gottesman, S. 1998. Regulation of proteolysis of the stationary-phase sigma factor RpoS. J. Bacteriol. 180:1154-1158. 